\title{
FIB Imaging of Deformation in Aluminum Alloys for Advanced Automotive Applications
}

\author{
M.W. Phaneuf*, S. Saimoto**, and R.K. Mishra*** \\ *Fibics Incorporated, 556 Booth St. Ottawa, ON Canada, K1A 0G1 \\ **Mechanical \& Materials Engineering, Queen's University, Kingston, ON, Canada K7L 3N6 \\ ***GM R\&D Center, Warren MI USA 48090
}

Focused ion beam (FIB) imaging of metals reveals a remarkable degree of grain orientation contrast [1,2 and incorporated references]. Applications of FIB imaging to the direct observation of deformation in metals are less well reported [3-6], but the effectiveness of the FIB technique as a tool to directly image the degree or extent of deformation is becoming accepted in industrial research and development.

Particularly for FCC metals, FIB secondary electron (and to a lesser extent secondary ion) images are sensitive to increased dislocation density and the presence of subgrain boundaries, revealing a "mottled" and less uniform contrast as the degree of deformation within a grain increases. This makes FIB imaging a useful and efficient means of evaluating large areas that would be impractical to observe by transmission electron microscopy (TEM).

Figure 1 is a FIB secondary electron image mosaic of a cross-section from a "U-bend" test specimen of AA5754 aluminum alloy sheet. The mosaic covers an area approximately $1.25 \mathrm{~mm} \times 1.25 \mathrm{~mm}$, and reveals a considerable amount of information regarding the degree of deformation and sub grain formation throughout the sheet thickness after deformation. Inset image 3 shows the relatively undisturbed material along the neutral axis of the sheet, whereas inset images 1 and 5 show the extremes of compressive and tensile deformation, respectively. The contrast inside the grains in inset image 3 is uniform but the grains in inset images 1, 2, 4 and 5 shows a mottled contrast characteristic of dislocation accumulation. The gradient in grain size and contrast differentials can be correlated with macroscopic deformation gradient in the bent sample.

Comparison of results obtained by this technique with TEM results for subsurface deformation during wear in aluminum and steel automotive alloys will also be presented to demonstrate the power of FIB imaging to map deformation distribution over large areas.

\section{REFERENCES}

1. Franklin, R.E., Kirk, E.C.G., Cleaver J.R.A., Ahmed, H., 1988, Channelling ion image contrast and sputtering in gold specimens observed in a high-resolution scanning ion microscope, J. Mat. Sci. Letters, 7, 39-41.

2. Phaneuf, M.W., 1999. Applications of focused ion beam microscopy to materials science specimens. Micron 30, 277-288.

3. Evans R.D., Phaneuf, M.W. Boyd, J.D., 1999. Imaging damage evolution in a small particle metal matrix composite, J. Microsc. 196 (2), (1999), pp. 146-154.

4. Engqvist, H., Botton, G.A., Ederyd, S., Phaneuf, M., Fondelius, J., Axen, N., 2000. Wear phenomena on WC-based face seal rings, Intl. J. Refract. Metals \& Hard Matls 18, 39-46.

5. Burke, M.G., Duda, P.T., Botton, G., and Phaneuf, M.W., 2000, Assesment of deformation using the focused ion beam technique, Microsc. Microanal. 6 (Suppl 2:Proc.), 530-531.

6. Introduction To Focused Ion Beams: Instrumentation, Theory, Techniques And Practice, Gianuzzi, L.A. and Stevie, F.A. Eds. (C) 2004 Springer Publishing Co., Inc. ISBN: 0387231161 


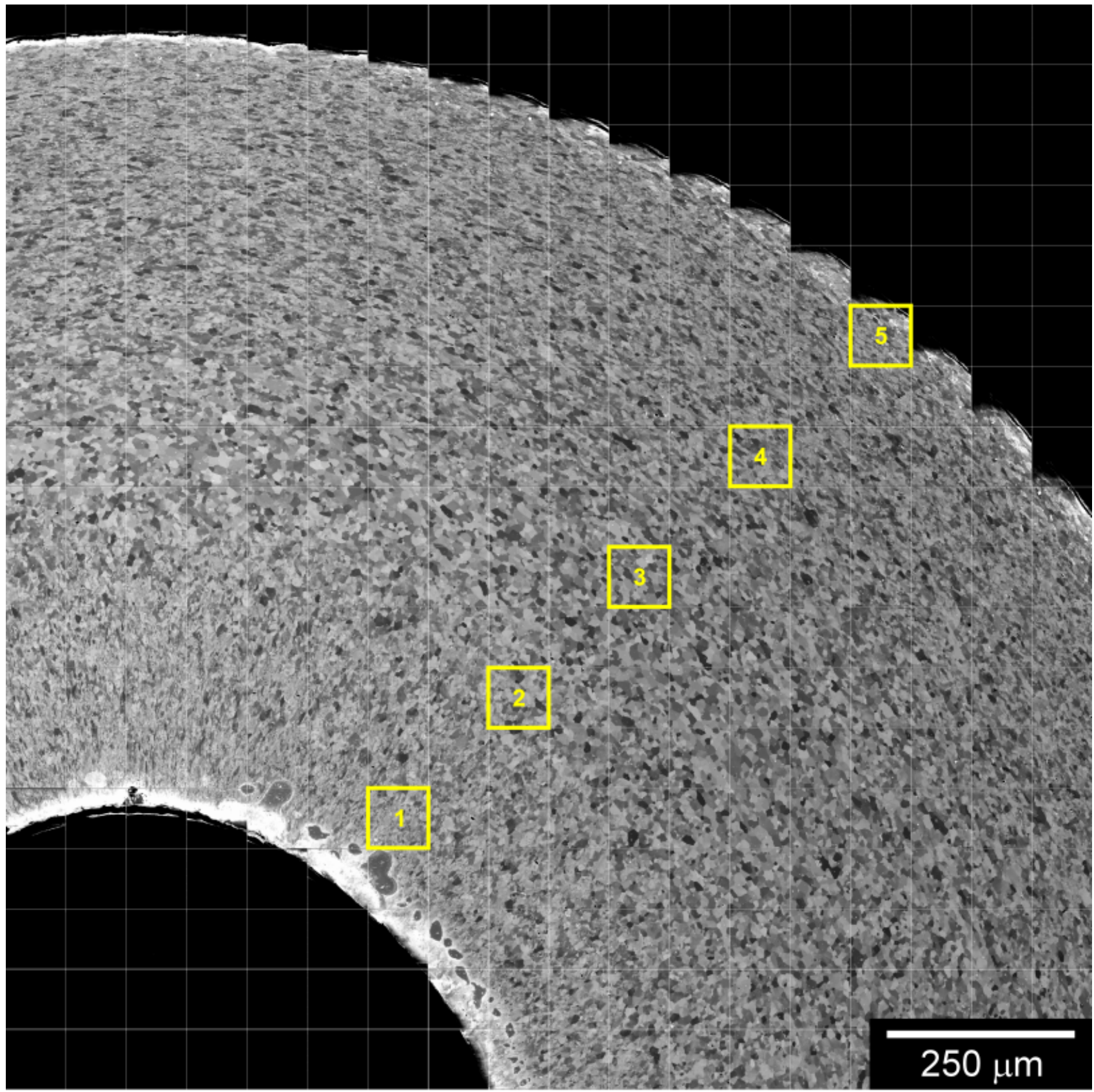

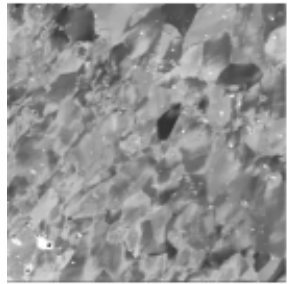

1

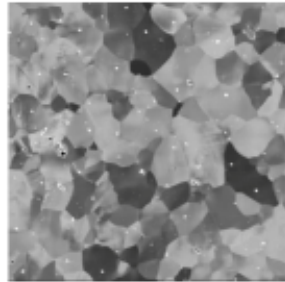

2

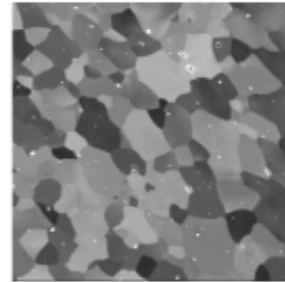

3

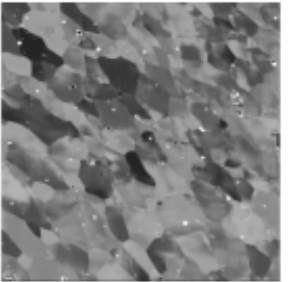

4

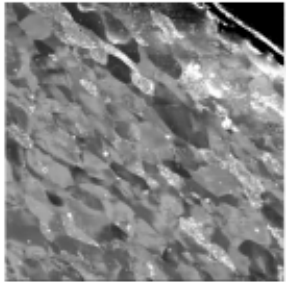

5

Figure 1: FIB secondary electron image mosaic of a cross-section from a "U-bend" test specimen of AA5754 aluminum alloy sheet. Note the relatively uniform grain orientation contrast visible in inset image 3 on the neutral axis of the sheet, versus the mottled contrast and grain deformation that increases as one moves towards the sheet surfaces. 